\title{
Metabolic Effects of Olanzapine and Quetiapine: A Six-Week Random- ized, Single Blind, Controlled Study
}

\author{
Halise Devrimci Ozguven*, Bora Baskak, Ozgur Oner and Cem Atbasoglu
}

Ankara University Faculty of Medicine, Psychiatry Department, Turkey

\begin{abstract}
The objective of this study is to compare the course of metabolic effects of olanzapine and quetiapine, two atypical antipsychotics with similar structure and receptor binding affinities but clinically observed different metabolic effects. This 6 week, single blind, randomized, controlled study was carried out during a structured treatment protocol in a female inpatient service, thus enabled to control effects of energy expenditure and other life style related factors. Subjects were randomly assigned into olanzapine $(n=15)$ and quetiapine $(n=15)$ groups. Weight and calorie intake $(C I)$ were measured daily. Symptom severity and serum leptin levels (SLL) were measured biweekly. Serum lipids were measured at baseline and 6th week. Olanzapine treatment was associated with more severe weight gain $(\mathrm{F}=11.2, \mathrm{p}<0.01)$, increase in $\mathrm{CI}(\mathrm{F}=8.1, \mathrm{p}<0.01)$ and a more disturbed lipid profile than quetiapine. The course of SLL were similar between the groups $(\mathrm{F}=1.39, \mathrm{p}=0.26)$. Weight, $\mathrm{CI}$ and SLL changed in a similar pattern within the groups but the patterns were different for each drug, suggesting that the two drugs have different mechanisms for weight change. The explanation probably involves different affinities for $5 \mathrm{HT} 2 \mathrm{C}$ receptors leading to different patterns of CI which we propose as possible targets of intervention to manage antipsychotic induced weight gain.
\end{abstract}

Keywords: Leptin, weight gain, olanzapine, quetiapine, metabolic syndrome.

\section{INTRODUCTION}

Adverse metabolic effects such as weight gain and dyslipidemia have increasingly been recognized with the use of atypical antipsychotic drugs. However various antipsychotics have distinct metabolic effects.

Olanzapine treatment has been consistently associated with weight gain [1] in a prolonged treatment period from the first weeks of the treatment up to the end of the first year [2]. The drug has been tested against conventional (eg; haloperidol) and some novel (eg; risperidone) antipsychotics and found to be associated with a more severe weight gain $[3,4]$. Pooled data from studies on weight change with olanzapine use revealed that $24-37 \%$ of the patients experienced weight gain of 7\% of their body weight [5]. Quetiapine appears to be a preferred antipsychotic in patients with metabolic syndrome [6]. Although quetiapine was found to be associated with a less predominant $[7,8]$ and dose dependent [9] weight gain, especially in short term treatment (first 6 weeks) [10], data on metabolic syndrome is less available compared to olanzapine. In a longer time period, use of quetiapine was associated with gains of $2-3 \mathrm{~kg}$ within twelve months of treatment [8]. To our knowledge, there is no head to head controlled prospective comparison of the metabolic effects of quetiapine and olanzapine.

Antagonism at the central $\mathrm{H}_{1}, 5-\mathrm{HT} 2 \mathrm{C}$, M1, and $\alpha 1-$ noradrenergic receptors have been suggested as possible molecular mechanisms of antipsychotic induced dysregula

*Address correspondence to this author at the Ankara University Faculty of Medicine, Psychiatry Department, Turkey. Tel: 903125957084; Fax:903123191933; E-mails: Ozguven@medicine.ankara.edu.tr tion of food intake and weight gain [11-14]. Particularly $\mathrm{H}_{1}$ antagonism may be playing a key role in weight gain since it mediates the orexigenic effects of AMP kinase, an enzyme involved in regulating food intake, while reversing the actions of leptin, an anorexigenic hormone [15]. Affinity for the $\mathrm{H}_{1}$ receptors is most closely related to antipsychotic induced weight gain and quetiapine and olanzapine have similar binding affinities for the $\mathrm{H}_{1}$ receptors [16]. Considering the affinity for $\mathrm{M} 1$ and $\alpha 1$-noradrenergic receptors; quetiapine is the closest antipsychotic agent to olanzapine for M1 receptors [17], and both drugs have strong affinity for $\alpha 1$ noradrenergic receptors [18]. Although the affinity of quetiapine is lower than olanzapine for the 5-HT2C receptors [17], in general, previous literature is quite consistent that quetiapine has similar structural and pharmaco-dynamic properties to olanzapine and clozapine. Besides, no two atypical antipsychotics possess the same portfolio of actions upon all of these neurotransmitter systems [19]. Therefore, we think that olanzapine and quetiapine are structurally and pharmacologically similar drugs with clinically observed different metabolic effects which make them suitable for a comparison under controlled settings.

There might be other factors associated with antipsychotic induced weight gain among which leptin appears to be one of the key determinants. This hormone has been previously tested in many studies and still is believed to play a central role [20]. Leptin reduces food intake and increases energy expenditure thus reduces body weight [21] by affecting the feeding behavior through activation of the central histaminergic system via $\mathrm{H}_{1}$ receptors [22]. It was suggested that leptin affects the feeding behavior through activation of the central histaminergic system via $\mathrm{H} 1$ receptors [22]. A 
potent H1 antagonist, olanzapine, has consistently been associated with an increase in serum leptin levels (SLL) starting as early as the 4th hour of treatment and remains somehow elevated after that period up to several months [23$25]$. On the other hand, another potent $\mathrm{H}_{1}$ antagonist quetiapine was studied once in a randomized, prospective study and the authors found a marked increase in SLL in the olanzapine vs. the quetiapine group [26]. Having revised a considerable amount of leptin research, Sentissi et al. [27] mentioned that, surprisingly, weight gain, body mass index (BMI) and other metabolic parameters were not systematically considered, and an objective evaluation of feeding behavior during antipsychotic treatment remains to be determined.

Antipsychotic use has also been associated with dyslipidemia. Olanzapine treatment was associated with a marked hypertriglyceridaemia and hypercholesterolaemia [28, 29]. On the other hand, Melkersson and Dahl [30] proposed that, quetiapine may be expected to affect lipid levels because of its structural similarities with olanzapine; however less data exists regarding quetiapine. Stroup et al. [31] determined that use of quetiapine was associated with increased cholesterol and triglyceride levels. The mechanism of antipsychotic induced hyperlipidemia is still not clear. Although dyslipidemia was generally accepted to be a result of weight gain, recent studies revealed that some antipsychotics may have direct and immediate effects on serum lipids independent from their effects on weight [6] and inter-relations between life style related factors, dyslipidemia, SLL and weight gain requires further investigation [16].

Although the pathophysiology of the metabolic side effects of atypical antipsychotic drugs is not completely understood, the final effect of olanzapine or quetiapine on the metabolic parameters is probably the end result of a complex interplay between many factors such as sedentary life style, diet related factors, endocrine factors and receptor profile of the antipsychotic drug. In this regard, a comparison of antipsychotics that have similar structures and receptor profiles but clinically observed different metabolic side effects may potentially be informative, especially when daily calorie intake and energy expenditure are controlled.

We compared the metabolic effects of olanzapine and quetiapine in a randomized, single blind prospective design, recording individual parameters such as diet and calorie intake, and controlling energy expenditure and other life style related factors. Besides we checked the effect of baseline BMI's on weight gain. The degree of clinical improvement was also monitored and compared between the groups.

\section{METHOD}

\section{Sample and Procedure}

Consecutive inpatients aged 18-65 within the indication spectrum of atypical antipsychotic monotherapy $(n=96)$ were screened for inclusion at Ankara University Psychiatry Department Female Inpatients Service. Patients with any overt metabolic or endocrine disorder diagnosed before or during hospitalization $(n=54)$ were excluded, as those who declined to provide written informed consent $(n=8)$. The study was approved by the local ethics committee.

Subjects were randomly assigned into olanzapine $(n=15)$ or quetiapine $(n=19)$ groups, using a predetermined number chart that was rearranged following a dropout for any reason. Randomization was stipulated to be carried out until a sample size of 30 patients (15 patients in each group) was secured at the end of the study. Primary DSM-IV TR diagnoses were Schizophrenia $(n=27)$, Schizoaffective Disorder $(n=2)$ and Schizophreniform Disorder $(n=1)$. The severity of psychotic symptoms as measured by Scales for the Assessment of Positive (SAPS) and Negative Symptoms (SANS) were not different between the two groups (Table 1).

The treatment procedure (i.e.; dosing, management of side effects, judgment for non response and decisions regarding antipsychotic medication change) was carried out by the assigned clinician. The patients who were added another antipsychotic agent or whose antipsychotic treatment was suspended were to be dropped out. Mean daily doses of the administered drugs were; $23.0 \pm 10.1 \mathrm{mg} /$ day for olanzapine and $826.7 \pm 326.2 \mathrm{mg} /$ day for quetiapine. No serious adverse events were examined in both groups. The intervention was discontinued in 4 patients in the quetiapine group due to lack of response (in 4 weeks) according to their physicians' decision based on inefficiency of treatment; the data of these patients were not included into the analyses. The interviewers, the laboratory personnel and the dietician were blind to the medication. As presented in Table 1; age, baseline weight and BMI's and clinical symptom severity of the two groups were similar.

\section{Clinical and Laboratory Assessments}

The study setting permitted a structured treatment protocol including the daily physical activity for all inpatients, as required by the "token economy system", part of the behavioral psychotherapy approach (for a review see [32]). Standard hospital diet (average $2000 \mathrm{kcal} /$ day) was served, however consumption of extra food and beverage was not restricted. Daily food intake was recorded and computed by the dietician in kilocalories (Kcal).

Weight, BMI and calorie intake were measured daily. Symptom severity and SLL were measured biweekly. Plasma total cholesterol (TC), triglyceride (TG), high density lipoprotein (HDL), low density lipoprotein (LDL), very low density lipoprotein (VLDL) levels and fasting blood glucose (FBG) levels were measured at baseline and at the sixth week. Weight was measured before breakfast at 8 am, with the same electronic weigher. Symptoms were assessed using the Scale for the Assessment of Positive Symptoms (SAPS) [33] and the Scale for the Assessment of Negative Symptoms (SANS) [34]. Overall changes in disease severity were assessed by Clinical Global Impressions Scale (CGI) [35].

\section{Analysis}

Statistical analyses were carried out with the SPSS 13.0 program. Symptom severity was compared between the groups at baseline and at the end of the sixth week by t-test. Continuous variables at baseline were compared with the ttest. Weight gain, calorie intake, and SLL were compared within and between the groups with repeated measures ANOVA. Although weight, BMI and calorie intake were recorded daily, biweekly measures were employed into the statistical analysis in order to allow a more accurate 
Table 1. Comparison of Olanzapine and Quetiapine Groups for Age, Weight, BMI and Symptom Severity Before They Were Allocated to Intervention (Independent Samples t-Test)

\begin{tabular}{|c|c|c|c|}
\hline & $\begin{array}{c}\text { Olanzapine } \\
(\mathbf{N}=\mathbf{1 5}) \\
(\text { Mean } \pm \text { SD) }\end{array}$ & $\begin{array}{c}\text { Quetiapine } \\
(\mathbf{N}=\mathbf{1 5}) \\
(\text { Mean } \pm \text { SD) }\end{array}$ & $\mathrm{t}=0.95, \mathrm{p}=0.35$ \\
\hline Age & $38.8 \pm 15.3$ & $33.9 \pm 13.0$ & $\mathrm{t}=-0.44, \mathrm{p}=0.66 \quad \mathrm{t}=-0.69, \mathrm{p}=0.50$ \\
\hline Weight $(\mathrm{kg})$ & $60.8 \pm 15.0$ & $63.2 \pm 13.3$ & $\mathrm{t}=0.80, \mathrm{p}=0.43$ \\
\hline BMI & $24.2 \pm 5.6$ & $25.7 \pm 6.1$ & $\mathrm{t}=0.49, \mathrm{p}=0.63$ \\
\hline CGI score & $5.9 \pm 0.7$ & $5.6 \pm 1.0$ & $\mathrm{t}=-0.85, \mathrm{p}=0.93$ \\
\hline SAPS score & $69.1 \pm 28.9$ & $63.7 \pm 30.6$ & $66.7 \pm 23.5$ \\
\hline SANS score & $65.9 \pm 28.1$ & & \\
\hline
\end{tabular}

SD:Standard deviation, BMI:Body mass index, CGI:Clinical global impressions, SAPS:Scale for the assessment of positive symptoms, SANS:Scale for the assessment of negative symptoms

Table 2. Comparison of Olanzapine and Quetiapine Groups for Weight Gain, BMI, Average Daily Calorie Intake and SLL During 6 Weeks (Repeated Measures ANOVA)

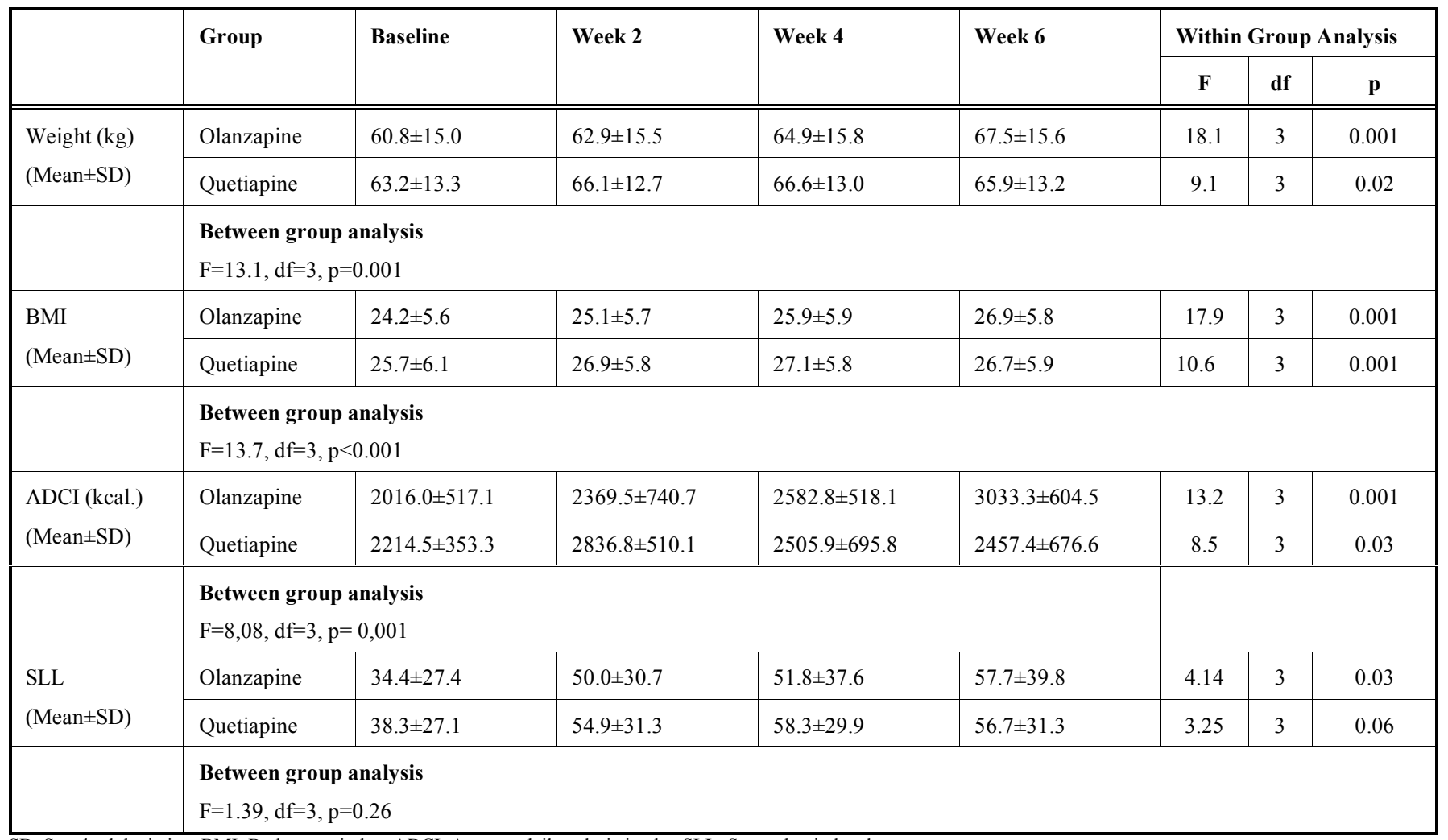

SD: Standard deviation, BMI: Body mass index, ADCI: Average daily calorie intake, SLL: Serum leptin levels.

comparison with the course of other metabolic parameters. In some previous studies baseline BMIs were found to affect antipsychotic induced weight gain [36, 37]. Therefore we have used Spearman Correlations Test to explore the relationship of weight change and baseline BMIs in both groups. In order to understand if baseline BMI affects the course of weight gain in both groups, we have employed baseline BMI as a covariate in repeated measures ANOVA. Serum lipid levels were compared between the groups at baseline and at the end of the study with the t-test and MannWhitney U Test where suitable.

\section{RESULTS}

Both olanzapine and quetiapine use were associated with weight gain (Fig. 1). We observed an average of 6.7 kilograms gained in the olanzapine group that was equivalent to $11.5 \%$ of the patients' body weight at baseline. The patients in the quetiapine group gained an average of 2.7 kilograms that was equivalent to $4.5 \%$ of their body weight. When analyzed within the groups; weight gain was statistically significant in both groups (olanzapine group, $\mathrm{F}=18.1, \mathrm{df}=3$, 


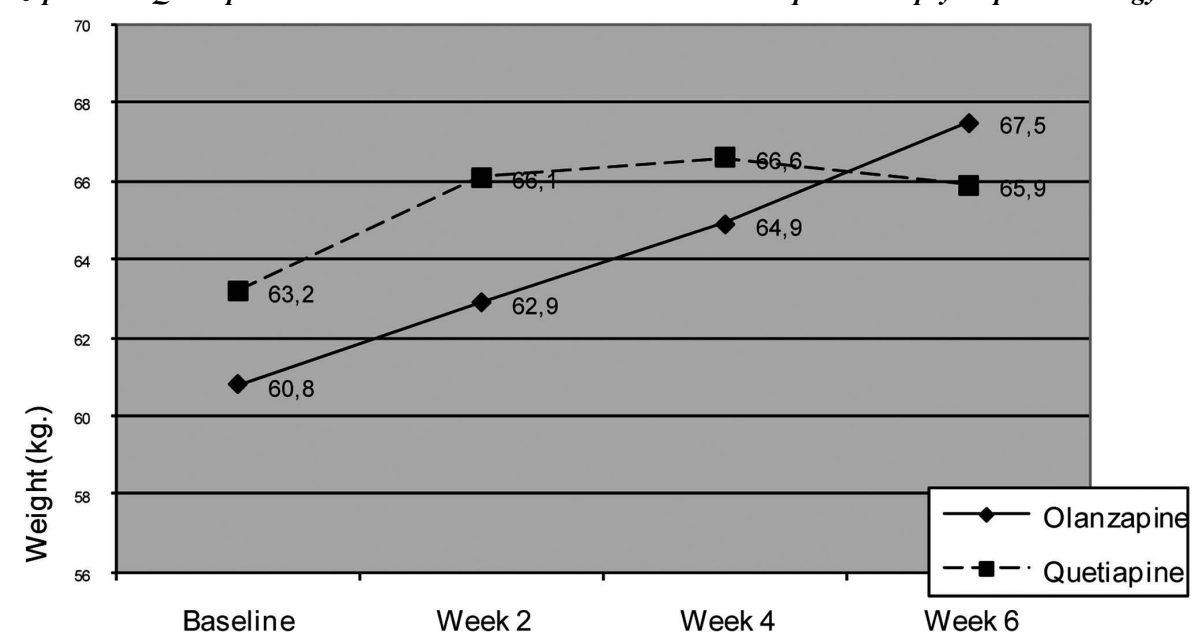

Fig. (1). The course of weight during 6 weeks in olanzapine and quetiapine groups.

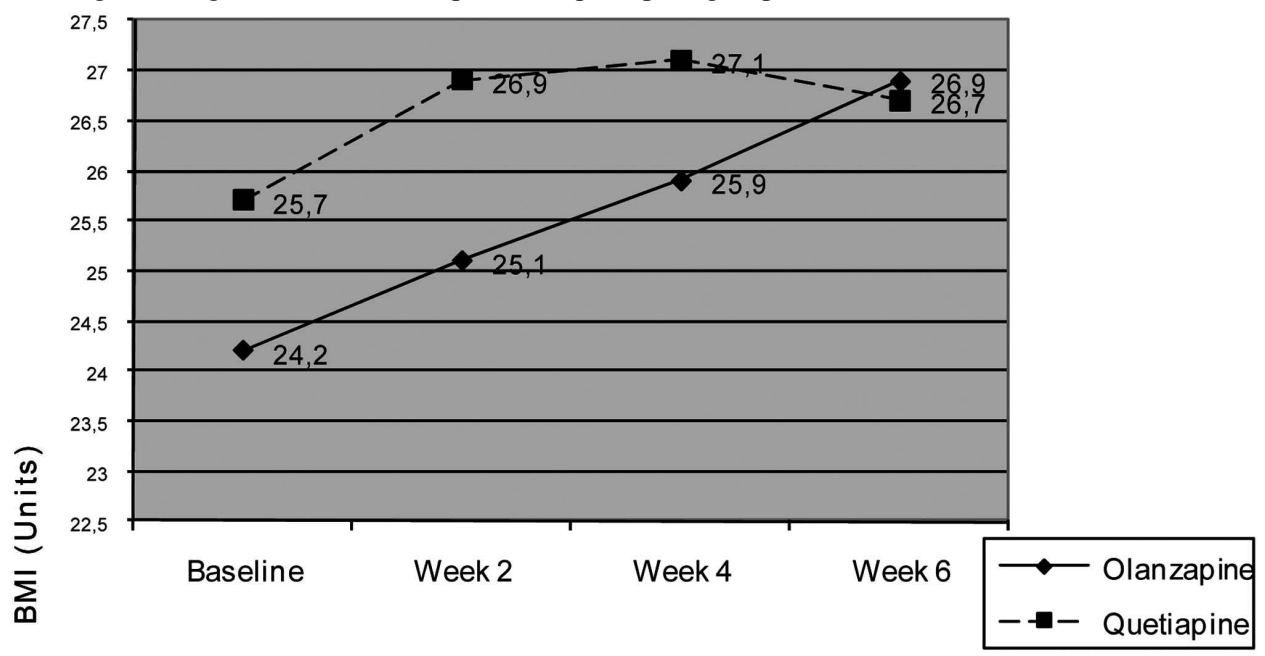

Fig. (2). The course of body mass index (BMI) during 6 weeks in olanzapine and quetiapine groups.

$\mathrm{p}=0.001$; quetiapine group, $\mathrm{F}=9.1, \mathrm{df}=3, \mathrm{p}=0.02$ ). However, use of olanzapine was associated with a more predominant weight change than quetiapine in six weeks $(\mathrm{F}=13.1, \mathrm{df}=3$, $\mathrm{p}=0.001$ ) (Table 2).

Changes in the BMI are summarized in Fig. (2). We observed an average BMI increase of 2.7 and 0.9 units in the olanzapine and quetiapine groups, respectively. Repeated measures analyses within the groups revealed statistical significance in both groups $(\mathrm{F}=17.9, \mathrm{df}=3, \mathrm{p}=0.001$ for olanzapine; $\mathrm{F}=10.6, \mathrm{df}=3, \mathrm{p}=0.001$ for quetiapine). Olanzapine was associated with a more predominant BMI change compared to quetiapine $(\mathrm{F}=13.7, \mathrm{df}=3, \mathrm{p}<0.001)$ (Table 2).

There was a significant increase in the average daily calorie intake in both groups $(\mathrm{F}=13.2, \mathrm{df}=3, \mathrm{p}=0.001$ for olanzapine and $\mathrm{F}=8.46, \mathrm{df}=3, \mathrm{p}=0.03$ for quetiapine) (Fig. 3 ). The mean increase at endpoint was $58.8 \%$ for olanzapine and $10.6 \%$ for quetiapine. The course of daily calorie intake between the groups was significantly different $(\mathrm{F}=8.08, \mathrm{df}=3$, $\mathrm{p}=0.001)$ (Table 2).

When analyzed within the groups; there was a significant change in SLL in the olanzapine group $(\mathrm{F}=4.14, \mathrm{df}=3$, $\mathrm{p}=0.03)$, but it was at the verge of statistical significance in the quetiapine group. $(\mathrm{F}=3.25, \mathrm{df}=3, \mathrm{p}=0.06)$. When analyzed between the groups; the course of SLL change during six weeks was similar in two groups $(\mathrm{F}=1.39, \mathrm{df}=3, \mathrm{p}=0.26)$
(Table 2). The course of SLL in both groups is presented in Fig. (4).

There were significant negative correlations between baseline BMIs and weight change in the whole sample $(\mathrm{r}=-0.50, \mathrm{p}=0.005)$ and the quetiapine group $(\mathrm{r}=-0.53$, $\mathrm{p}=0.043$ ) and a negative correlation was observed at the verge of statistical significance in the olanzapine group $(\mathrm{r}=$ $0.49, \mathrm{p}=0.06$ ). In order to explore the effect of baseline BMIs on the course of weight change during six weeks; we have repeated the ANOVA with weight as the dependent variable and time (groups) as the independent variable, covarying for baseline BMI. When BMI was covaried, the statistical significance within the groups disappeared (olanzapine group; $\mathrm{F}=1.98, \mathrm{df}=3, \mathrm{p}=0.17$, quetiapine group; $\mathrm{F}=2.48, \mathrm{df}=3$, $\mathrm{p}=0.11)$. However there was still a significant difference for the course of weight gain between the groups $(F=12.30$, $\mathrm{df}=3, \mathrm{p}<0.001)$.

The change in metabolic parameters and lipid profiles between the first and the sixth week are presented in Table 3. Olanzapine treatment was found associated with a more predominant raise in $\mathrm{TC}(\mathrm{T}=2.66, \mathrm{p}=0.013)$ and $\mathrm{LDL}$ levels $(\mathrm{T}=2.1, \mathrm{p}=0.044)$ than quetiapine.

The degree of clinical improvement was also monitored and compared between the groups. Repeated measures with ANOVA revealed a significant decline in six weeks in posi- 


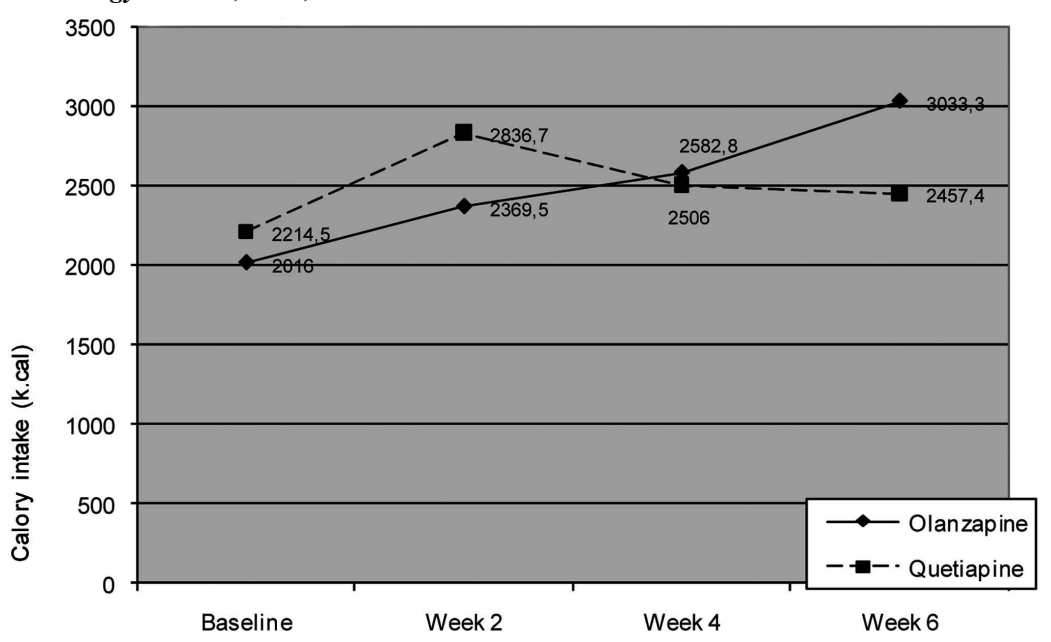

Fig. (3). The course of calory intake during 6 weeks in olanzapine and quetiapine groups.

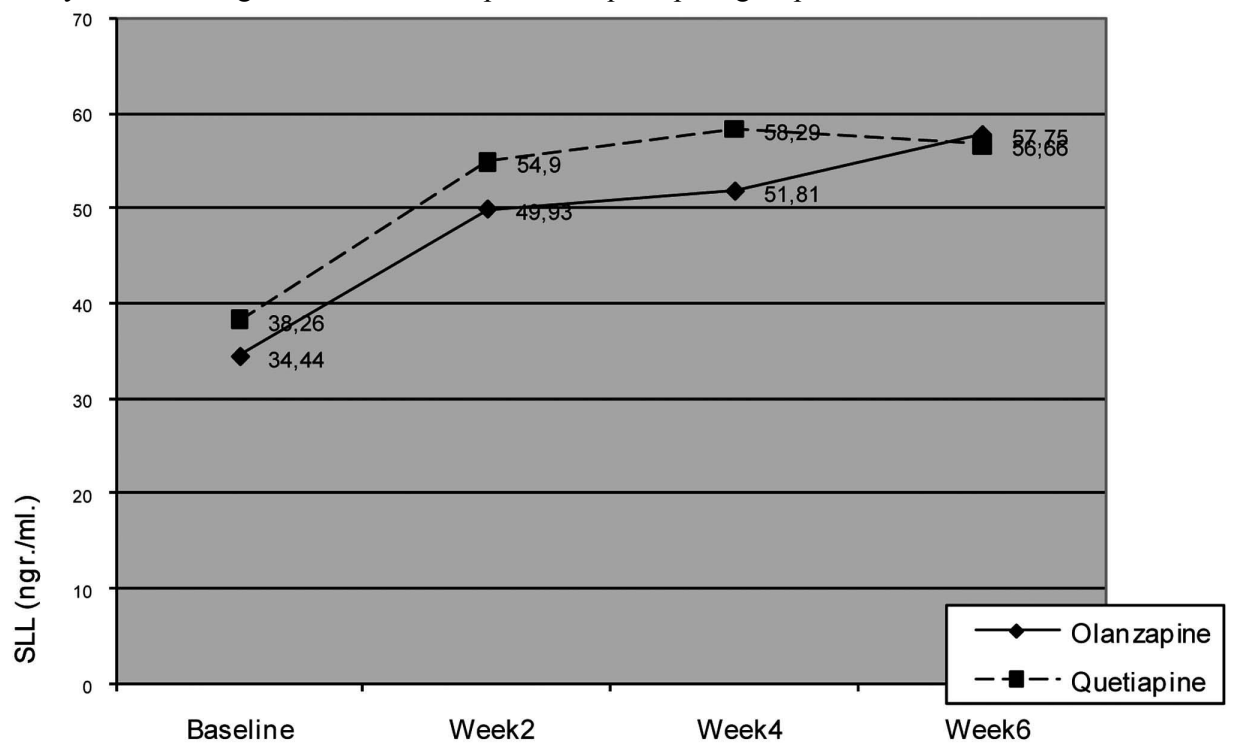

Fig. (4). T he course of serum leptin leve(1SsL L) during six weeks in olanzapine andquetiapine groups.

tive symptoms (olanzapine group, $\mathrm{F}=24.4, \mathrm{df}=3, \mathrm{p}<0.001$; quetiapine group, $\mathrm{F}=5.75, \mathrm{df}=3, \mathrm{p}=0.011)$ and negative symptoms (olanzapine group, $\mathrm{F}=7.33, \mathrm{df}=3, \mathrm{p}=0.005$; quetiapine group, $\mathrm{F}=5.44, \mathrm{df}=3, \mathrm{p}=0.014)$. When both drugs are compared; olanzapine treatment was associated with a more significant decline in positive symptoms than quetiapine $(\mathrm{F}=5.69, \mathrm{df}=3, \mathrm{p}=0.004)$. The effect on negative symptoms were similar in both groups $(\mathrm{F}=1.01, \mathrm{df}=3, \mathrm{p}=0.40)$. Response was defined as at least a $20 \%$ change in SAPS and SANS scores from baseline. The rate of the responders for the positive symptoms were $100 \%$ for the olanzapine group and $53.3 \%$ for the quetiapine group $\left(X^{2}=9.19, p=0.03\right)$. The rate of the responders for the negative symptoms were $73.3 \%$ for the olanzapine group and $60 \%$ for the quetiapine group $\left(\mathrm{X}^{2}=0.60, \mathrm{p}=0.44\right)$. As measured by the CGI; there was an average of $46.7 \%$ decline in the olanzapine group and $17.1 \%$ decline in the quetiapine group for overall disease severity.

\section{DISCUSSION}

In a randomized, single blind design, controlling the individual parameters of calorie intake and energy expenditure in a uniform environment, we compared the metabolic effects of olanzapine and quetiapine.
Repeated measurements of weight, calorie intake and SLL allowed us to evaluate the change of those 3 parameters in 6 weeks together. A similar course is visible in Figs. (1-4). When Figs. (1-4) are examined together, it can be concluded that the course of those 3 parameters are similar within the groups. However the courses of those parameters are different for these two drugs. Within a 6 weeks treatment period, in the olanzapine group, it is observable that weight, calorie intake and SLL rise continuously and linearly, while those three parameters rise and then start to fall after the $2^{\text {nd }}$ week but still stay above the initial levels in the quetiapine group. This finding suggests that, even they share similar pharmacologic properties; olanzapine and quetiapine have specific but different mechanisms for weight change. Although it was previously proposed that different effects of different antipsychotics on weight gain may be related to H1, M1 and $\alpha-1$ noradrenergic receptor affinities [12-14]; our findings suggest that, different characteristics of olanzapine and quetiapine on weight gain do not -at least directly- rely on different binding affinities to $\mathrm{H} 1, \mathrm{M} 1$ and $\alpha-1$ noradrenergic receptors. 5-HT2C receptor affinities might be important for different effects of the two drugs on weight gain. When baseline BMI was covaried into the analyses the significant change of weight was still observable between the groups, therefore 
Table 3. Comparison of Olanzapine and Quetiapine Groups for TC, LDL, HDL, VLDL, TG and FBG Change Between Baseline and the $6^{\text {th }}$ Week

\begin{tabular}{|c|c|c|c|c|}
\hline $\begin{array}{l}\text { TC } \\
(\text { Mean } \pm \text { SD) }\end{array}$ & Baseline & $184.7 \pm 35.3$ & $181.4 \pm 49.9$ & $\begin{array}{l}\mathrm{T}=2.66^{*} \\
\mathrm{p}=0.013\end{array}$ \\
\hline $\begin{array}{l}\text { LDL } \\
(\text { Mean } \pm \mathrm{SD})\end{array}$ & Baseline & $108.6 \pm 38.1$ & $102.9 \pm 33.6$ & $\begin{array}{l}\mathrm{T}=2.1^{*} \\
\mathrm{p}=0.044\end{array}$ \\
\hline $\begin{array}{l}\text { HDL } \\
(\text { Mean } \pm \text { SD) }\end{array}$ & $6^{\text {th }}$ week & $54.1 \pm 12.3$ & $48.8 \pm 11.1$ & $\begin{array}{l}\mathrm{T}=1.68^{*} \\
\mathrm{p}=0.103\end{array}$ \\
\hline \multirow{2}{*}{$\begin{array}{l}\text { VLDL } \\
\text { (Median, Range) }\end{array}$} & Baseline & $22,(11-40)$ & $16,(8-107)$ & \multirow{2}{*}{$\begin{array}{l}Z=-0.48^{* *} \\
p=0.65\end{array}$} \\
\hline & $6^{\text {th }}$ week & $28,(12-52)$ & $21,(14-136)$ & \\
\hline $\begin{array}{l}\text { FBG } \\
\text { (Median, Range) }\end{array}$ & $6^{\text {th }}$ week & $91,(73-118)$ & $87,(72-106)$ & $\begin{array}{l}Z=-0.62 * * \\
p=0.97\end{array}$ \\
\hline
\end{tabular}

TC: Total cholesterol, LDL: Low density lipoprotein, HDL: High density lipoprotein, VLDL: Very low density lipoprotein, TG: Triglyceride, FBG: Fasting blood glucose, SD= Standard deviation, $*=$ ANOVA with repeated measures within the groups, $* *=$ Independent samples $\mathrm{t}$ test $* *=$ Mann-Whitney $\mathrm{U}$ Test.

baseline BMI cannot be accounted for the explanation of different weight gain patterns of the two drugs. Life style related factors and energy expenditure were controlled in this study and different effects of olanzapine and quetiapine on weight gain are likely not related to these factors.

When Figs. $(\mathbf{3}, \mathbf{4})$ and Table $\mathbf{2}$ are examined together, it is evident that as early as the patients in both groups start to gain weight, SLL also begin to rise simultaneously. This is an expected finding since leptin is accepted as a response to weight gain. But unexpectedly, calorie intake also follows the same pattern. In fact, the opposite might have been expected since leptin was supposed to effect feeding behavior via its effects on central nervous system [38]. Therefore our results suggest that antipsychotic treatment may have prevented leptin from performing its expected anorexigenic effects. A possible explanation may involve a competition between antipsychotics and leptin for the central H1 receptors [13]. But considering the discussion in the previous paragraph, this is probably not the only mechanism. A more valid explanation likely involves a complicated interaction of different factors which were previously linked to antipsychotic induced weight gain such as; effects of 5-HT2C receptors, POMC, cytokine systems [39], adiponectin and ghrelin [17]. In a similar line of argument, Esen-Danaci et al measured leptin and gherelin levels in patients taking different antipsychotics and showed that the weight-gain side effect of atypical antipsychotics can be related with the orexigenic effect of elevated serum ghrelin rather than leptin deficit [40].

An interesting result in our study is the negative correlation of baseline BMIs and weight change (Table 3). This finding is parallel to some previous studies $[36,37]$. It was suggested that obese individuals may be resistant to the anorexigenic effect of leptin [41]. But if this had been the case explaining antipsychotic induced weight gain, a positive correlation would have been expected. In fact Allison et al. [42] proposed that the negative correlations between baseline BMI and weight change observed in some previous studies may be a statistical artifact, namely; regression to the mean. To overcome this artifact, we have employed baseline BMI as a covariate into repeated measures with ANOVA. In this condition; the significant change in weight observed within the groups disappeared. Though this finding supports the hypothesis that baseline BMIs do have an effect on the course of antipsychotic induced weight change, this should be replicated in larger samples before coming to a conclusion. But for the present, it may suggest the clinicians to better be cautious before prescribing olanzapine and quetiapine to patients with low weight since these patients may be more prone to weight gain.

When Fig. (3) is examined, we see that calorie intake starts to increase significantly at the first week after the initiation of the antipsychotic treatment in both groups. Thus; among all the variables investigated in this study feeding behavior is probably the target for intervention and it is important to control feeding behavior from the first days after the initiation of antipsychotic treatment.

Our results reveal that both drugs are associated with weight gain but olanzapine is associated with a more predominant weight gain than quetiapine and this result is parallel to previous findings $[1,7]$. When two drugs are compared for their effects on serum lipids, it is evident that olanzapine disturbs lipid profile more seriously than quetiapine. This finding is in line with previous studies [30]. Widely used guidelines for metabolic side effects of antipsychotic drugs [43] recommend monitoring the lipid profiles of patients before treatment and at week 12. But our results reveal that the unwanted effects of olanzapine and quetiapine on serum 
lipids start as early as the $6^{\text {th }}$ week of treatment suggesting the need for a more conservative approach.

We did not observe a significant change in FBG in both groups within the first 6 weeks of treatment. This finding is in line with previous studies [1] and suggests that raise in FBG levels is a relatively delayed response to antipsychotic treatment.

This study has limitations. First of all, the sample size is small. So the results must be considered as preliminary findings. Different dosages of the two drugs might also have interfered with the metabolic parameters. The external validity of the study is low since the sample consists of female inpatients. In details, it may be proposed that; before hospitalization, the patients were in a psychotic episode that probably had an effect in feeding behavior. It may also be suggested that changes in diet composition (ie; from home diet to hospital diet) might have biased all results. In fact, we preferred this kind of design to keep internal validity high, since we aimed to contribute the understanding of interplay of different metabolic parameters on weight gain. Since management of antipsychotic induced metabolic syndrome relies explicitly on the underlying mechanisms, we finally would like to emphasize the need for studies designed in stable settings, controlling as many metabolic, pharmacodynamic and life style related factors as possible in order to better understand timing and mechanisms of antipsychotic induced metabolic side effects.

\section{ACKNOWLEDGEMENTS}

This is an investigator initiated trial partially supported by Astra Zeneca-Turkey and Lilly-Turkey. Investigators are responsible for the design and conduct of the trial and the primary analyses. There is no industry involvement in these activities. We wish to acknowledge the contributions of Astra Zeneca-Turkey and Lilly-Turkey.

\section{CONFLICTS OF INTERESTS}

Dr Ozguven reports she has received speaking fees from Glaxo Smith Klein Turkey, Janssen Pharmaceutica Turkey, Lundbeck Turkey, and clinical research fees from Astra Zeneca Turkey, Servier Turkey, Lundbeck Turkey, Janssen Pharmaceuticals Turkey. Dr. Baskak reported no biomedical financial interests or potential conflicts of interest. Dr Oner reported no biomedical financial interests or potential conflicts of interest. Dr. Atbasoglu reports he has received speaking and advising fees from AstraZeneca Turkey, Lilly Turkey, Bristol-Myers Squibb, Janssen Pharmaceutica, Pfizer, Vanda, and Wyeth, and clinical research fees from Astra Zeneca Turkey, Servier Turkey, Lundbeck Turkey, and Janssen Pharmaceuticals Turkey.

\section{REFERENCES}

[1] Newcomer JW. Second-generation (atypical) antipsychotics and metabolic effects: a comprehensive literature review. CNS Drugs 2005; 19(1): 1-93.

[2] Taylor DM, McAskill R. A typical antipsychotics and weight gaina systematic review. Acta Psychiatr Scand 2000; 101: 416-32.

[3] Wirshing DA, Wirshing WC, Kysar L, et al. Novel antipsychotics: comparison of weight gain liabilities. J Clin Psychiatry 1999; 60(6): 358-63.

[4] Sikich L, Hamer RM, Bashford RA, Sheitman BB, Lieberman JA. A pilot study of risperidone, olanzapine, and haloperidol in psy- chotic youth: a double-blind, randomized, 8-week trial. Neuropsychopharmacology 2004; 29(1): 133-45.

[5] Haddad P. Weight change with atypical antipsychotics in the treatment of schizophrenia. J Psychopharmacol 2005; 19(6): 16-27.

[6] de Leon J, Susce MT, Johnson M, et al. A clinical study of the association of antipsychotics with hyperlipidemia. Schizophr Res 2007; 92(1-3): 95-102.

[7] Allison DB, Mentore JL, Heo M, et al. Antipsychotic-induced weight gain: a comprehensive research synthesis. Am J Psychiatry 1999; 156: 1686-96.

[8] Haupt DW. Differential metabolic effects of antipsychotic treatments. Eur Neuropsychopharmacol 2006; 16(3): S149- S155.

[9] Small JG, Hirsch SR, Arvanitis LA, Miller BG, Link CGG. The Seroquel Study Group. Quetiapine in patients with schizophrenia: a high- and low-dose double-blind comparison with placebo. Archives of General Psychiatry 1997; 54: 549-57.

[10] Wetterling T. Bodyweight gain with atypical antipsychotics, A comparative review. Drug Saf 2001; 24(1): 59-73.

[11] Tecott LH, Sun LM, Akana SF, Strack AM, Lowenstein DH, Dallman MF, et al. (1995) Eating disorders and epilepsy in mice lacking 5-HT2c serotonin receptors. Nature 1995; 374: 542-6.

[12] Kroeze WK, Hufeisen SJ, Popadak BA, et al. H1-histamine receptor affinity predicts short-termweight gain for typical and atypical antipsychotic drugs. Neuropsychopharmacology 2003; 28(3): 51926.

[13] Matsui-Sakata A, Ohtani H, Sawada Y. Receptor occupancy-based analysis of the contributions of various receptors to antipsychoticsinduced weight gain and diabetes mellitus. Drug Metab Pharmacokinet 2005; 20(5): 368-78.

[14] Han M, Deng C, Burne THJ, Newell KA, Huang X-F. Short- and long-term effects ofantipsychotic drug treatment on weight gain and $\mathrm{H} 1$ receptor expression. Psychoneuroendocrinology 2008; 33: 569-80.

[15] Kim SF, Huang AS, Snowman AM, Teuscher C, Snyder SH. Antipsychotic drug-induced weight gain mediated by histamine H1 receptor-linked activation of hypothalamic AMP-kinase. Proc Natl Acad Sci USA 2007; 104: 3456-9.

[16] Nasrallah HA. Atypical antipsychotic-induced metabolic side effects: Insights from receptor-binding profiles. Mol Psychiatry 2008; 13(1): 27-35.

[17] Reynolds GP, Kirk SL. Metabolic side effects of antipsychotic drug-Pharmacological mechanisms. Pharmacol Ther 2010; 125(1): 169-79..

[18] Buckley PF, Foster A. Quetiapine. In: A textbook of psychopharmacology Schatzberg AF, Nemeroff CB, Eds. American Psychiatric Association (in press).

[19] Shayegan DK, Stahl SM. Atypical antipsychotics: matching receptor profile to individual patient's clinical profile. CNS Spectr 2004; 9(10 Suppl 11): 6-14.

[20] Jin H, Meyer JM, Mudaliar S, Jeste DV. Impact of atypical antipsychotic therapy on leptin, ghrelin, and adiponectin. Schizophr Res 2008; 100: 70-85.

[21] Baptista T, Lacruz A, Angeles F, et al. Endocrine and metabolic abnormalities involved in obesity associated with typical antipsychotic drug administration. Pharmacopsychiatry 2001; 34(6): 22331.

[22] Morimoto T, Yamamoto Y, Mobarakeh JI, et al. Involvement of the histaminergic system in leptin-induced suppression of food intake. Physiol Behav 1999; 67(5): 679-83.

[23] Wang HC, Chen PS, Lee IH, Yang YK, Yeh TL, Lu RB. Rapid leptin elevation after initiation of olanzapine? Neuropsychobiology 2006; 54: 182-5.

[24] Atmaca M, Tezcan E, Ustundag B. Plasma nitric oxide and leptin values in patients with olanzapine-induced weight gain. J Psychiatry Res 2007; 41: 74-9.

[25] Baptista T, Dávila A, El Fakih Y, et al. Similar frequency of abnormal correlation between serum leptin levels and BMI before and after olanzapine treatment in schizophrenia. Int Clin Psychopharmacol 2007; 22(4): 205-11.

[26] Atmaca M, Kuloglu M, Tezcan E, Ustundag B. Serum leptin and triglyceride levels in patients on treatment with atypical antipsychotics. J Clin Psychiatry 2003; 64: 598-604.

[27] Sentissi O, Epelbaum J, Olié JP, Poirier MF. Leptin and ghrelin levels in patients with schizophrenia during different antipsychotics treatment: a review. Schizophr Bull 2008; 34(6): 1189-99. 
[28] Osser DN, Najarian DM, Dufresne RL. Olanzapine increases weight and serum triglyceride levels. J Clin Psychiatry 1999; 60(11): 767-70.

[29] Meyer JM, Davis VG, McEvoy JP, et al. Impact of antipsychotic treatment on nonfasting triglycerides in the CATIE Schizophrenia trial phase 1. Schizophr Res 2000; 103(1-3): 104-9.

[30] Melkersson K, Dahl ML. Adverse metabolic effects associated with atypical antipsychotics: literature review and clinical implications. Drugs 2004; 64(7): 701-23.

[31] Stroup TS, Lieberman JA, McEvoy JP, et al. Effectiveness of olanzapine, quetiapine, and risperidone in patients with chronic schizophrenia after discontinuing perphenazine: a CATIE study. Am J Psychiatry 2007; 164: 415-27.

[32] Corrigan PW. Use of a token economy with seriously mentally ill patients: Criticisms and misconceptions. Psychiatric Serv 1995; 46: 1258-63.

[33] Andreasen NC. Scale for the Assessment of Positive Symptoms (SAPS), Iowa City: University of Iowa 1984.

[34] Andreasen NC. Scale for the Assessment of Negative Symptoms (SANS). iowa City: University of iowa 1984.

[35] Guy W. Clinical Global Impression. In: ECDEU Assessment manual for psychopharmacology. Guy W, Ed. Rockville; US Department of Health, Education and Welfare, Public Health Service, Alcohol, Drug Abuse and Mental Health Administration, NIMH Psychopharmacology Research Branch. Division of Extramural Research Programms 1976; pp. 218-22.

[36] Lane HY, Chang YC, Cheng YC, Liu GC, Lin XR, Chang WH.Effects of patient demographics, risperidone dosage, and clini- cal outcome on body weight in acutely exacerbated schizophrenia. J Clin Psychiatry 2003; 64: 316-20.

[37] Lee E, Leung CM, Wong E. A typical antipsychotics and weight gain in Chinese patients: a comparison of olanzapine and risperidone. J Clin Psychiatry 2004; 65: 864-6.

[38] Friedman JM. The function of leptin in nutrition, weight, and physiology. Nutr Rev 2002; 60(10): 1-14.

[39] Kluge M, Schuld A, Schacht A, et al. Effects of clozapine and olanzapine on cytokine systems are closely linked to weight gain and drug-induced fever. Psychoneuroendocrinology 2009; 34(1): 118-28.

[40] Esen-Danaci A, Sarandöl A, Taneli F, Yurtsever F, Ozlen N. Effects of second generation antipsychotics on leptin and ghrelin. Prog Neuropsychopharmacol Biol Psychiatry 2008; 32(6): 1434-8.

[41] Meier U, Gressner AM. Endocrine regulation of energy metabolism: review of pathobiochemical and clinical chemical aspects of leptin, ghrelin, adiponectin, and resistin. Clin Chem 2004; 50(9): 1511-25.

[42] Allison DB, Loebel AD, Lombardo I, Romano SJ, Siu CO. Understanding the relationship between baseline BMI and subsequent weight change in antipsychotic trials: effect modification or regression to the mean? Psychiatry Res 2009; 170(2-3): 172-6.

[43] American Diabetes Association, American Psychiatric Association, American Association of Clinical Endocrinologists, and North American Association for The Study of Obesity. Consensus development conference on antipsychotic drugs and obesity and diabetes. Diabetes Care 2004; 27: 596-601.

(C) Ozguven et al.; Licensee Bentham Open.

This is an open access article licensed under the terms of the Creative Commons Attribution Non-Commercial License (http://creativecommons.org/licenses/by-nc/3.0/) which permits unrestricted, non-commercial use, distribution and reproduction in any medium, provided the work is properly cited. 